\title{
Gestação: um desafio imunológico
}

\section{Pregnancy: an immune challenge}

\author{
Maria Angelica Ehara Watanabe ${ }^{1}$; Ellen Cristine Duarte-Garcia²; Giovana Gomes \\ de Carvalho ${ }^{3}$; Natália Kimie Matsubara ${ }^{4}$; Ana Camila Vaitkevicius Ferreira ${ }^{5}$; Nágela \\ Ghabdan Zanluqui ${ }^{6}$; Gabriela Gonçalves de Oliveira ${ }^{7}$
}

\begin{abstract}
Resumo
Diversos estudos demonstram a importância de aspectos imunológicos na gestação. Durante a gestação ocorre a implantação do embrião no útero materno, onde irá se desenvolver até o final da gravidez. Dentre os aspectos imunes, pode-se citar a importância da modulação dos linfócitos $T$, das células natural killers (NK) e das diversas citocinas existentes no organismo materno. A tolerância materna ao feto parece ser mediada por hormônios maternos específicos e pela expressão do antígeno leucocitário humano G (HLA-G) característico na gravidez. Outros estudos sugerem que a rejeição fetal e complicações durante a gravidez podem ocorrer devido à presença de antígenos de histocompatibilidade menor (mHAg), adquiridos pela mãe a partir do compartilhamento sanguíneo com o feto, e devido à presença de anticorpos maternos contra o espermatozoide e contra o feto. O objetivo desta revisão é descrever os aspectos imunológicos que permitem a tolerância materna ao feto na gestação, assim como possíveis causas para a rejeição do embrião e complicações durante a gravidez.
\end{abstract}

Palavras-chave: Gestação. Imunologia. HLA-G. Anticorpos. Citocinas.

\begin{abstract}
Several studies demonstrate the importance of immunological aspects of pregnancy. During pregnancy, the embryo is implanted in the womb, where it will develop until the end of pregnancy. Amongst the immune aspects, the importance of the modulation of $\mathrm{T}$ lymphocytes, natural killers (NK) cells and many cytokines in maternal organism can be mentioned. The maternal tolerance to the fetus appears to be mediated by specific maternal hormones and by the expression of human leukocyte antigen $G$ (HLA-G) - characteristic in pregnancy. Other studies suggest that fetal rejection and complications during pregnancy may occur because of the presence of minor histocompatibility antigens (mHAg), acquired by blood sharing of the mother with the fetus, and because of the presence of maternal antibodies against the sperm and against the fetus. The purpose of this review is to describe the immunological aspects that allow maternal tolerance to the fetus during pregnancy, as well as possible causes for rejection of the embryo and complications during pregnancy.
\end{abstract}

Key words: Pregnancy. Immunology. HLA-G. Antibodies. Cytokines.

\footnotetext{
${ }^{1}$ Doutora em Ciências Biológicas (Bioquímica) pela Universidade de São Paulo, Brasil. Professor Associado do Departamento de Ciências Patológicas da Universidade Estadual de Londrina. E-mail: maewatuel@gmail.com

${ }^{2}$ Graduanda em Biomedicina Centro de Ciências Biológicas Universidade Estadual de Londrina.

${ }^{3}$ Graduando em Biomedicina Centro de Ciências Biológicas Universidade Estadual de Londrina

${ }^{4}$ Graduando em Biomedicina Centro de Ciências Biológicas Universidade Estadual de Londrina

${ }^{5}$ Graduando em Biomedicina Centro de Ciências Biológicas Universidade Estadual de Londrina

${ }^{6}$ Graduando em Biomedicina Centro de Ciências Biológicas Universidade Estadual de Londrina

${ }^{7}$ Doutora em Patologia Experimental pela Universidade Estadual de Londrina. Pós doutoranda no Laboratório de Imunoparasitologia, na Faculdade de Medicina de Ribeirão Preto- USP.
} 


\section{Introdução}

A gravidez é o processo de desenvolvimento e crescimento de um ou mais embriões dentro do útero materno. Para que este processo ocorra de maneira adequada e o feto seja mantido durante todo o período de formação no organismo materno, é necessário que ocorra um equilíbrio hormonal e imunológico (MICHELON et al., 2006).

Para que haja a ovulação e fecundação é necessário a participação de alguns hormônios como o hormônio liberador de gonadotrofinas $(\mathrm{GnRH})$, o hormônio luteinizante (LH) e o hormônio folículo estimulante (FSH), os quais também auxiliam o processo de desenvolvimento e maturação de espermatozoides (GUYTON; HALL, 2006).

Sob a ótica da imunologia, o feto pode ser considerado como um enxerto semi-alogênico no organismo materno, já que possui o DNA paterno expressando seus antígenos, e que normalmente não é rejeitado. Para que ocorra essa aceitação materna, é necessário que ocorra modulação sob vários aspectos (ALVES et al., 2007), como a influência hormonal sobre o sistema imune materno, o reconhecimento das moléculas do Complexo de Histocompatibilidade paterno, as citocinas, as células Natural Killers uterinas e o papel das células $\mathrm{T}$ regulatórias (MICHELON et al., 2006). Os principais hormônios descritos que participam deste processo são a progesterona (DAHER; MATTAR, 2009) e a gonadotrofina coriônica (HCG) (NEVES; MEDINA; DELGADO, 2007).

As células $\mathrm{T}$ helper (Th) são responsáveis por coordenar a resposta imunológica do organismo. Observa-se na gravidez um predomínio do padrão imunológico de células Th2, que garante que seja estabelecida uma resposta mais branda ao organismo estranho inserido no útero materno (ZENCLUSSEN et al., 2002). Este tipo celular irá estimular a produção de fator de crescimento transformante beta (TGF- $\beta$ ), uma citocina que vai exercer papel fundamental na imunomodulação e na formação da estrutura maternofetal (BOIRIVANT et al.,1998; GRANDE, 1997).
Durante a embriogênese ocorre a formação do trofoblasto e suas especializações (NASSAR JÚNIOR; MIRANDA; MACÉA, 2002; MOORE; PERSAUD, 2004). Observa-se a expressão da molécula de HLA-G, a qual desempenha importante papel impedindo a ativação das células NK contra o embrião (DAHER; MATTAR, 2009).

O balanço dos fatores expostos, além da expressão de outras moléculas de histocompatibilidade menor, fatores da própria estrutura fetal e placentária, presença de anticorpos bloqueadores, entre outros, determinarão o sucesso ou não da futura gestação (MICHELON et al., 2006).

A imunologia da gestação envolve vários aspectos, tanto moleculares como celulares. Neste contexto, a proposta do presente trabalho é descrever os aspectos imunológicos que permitem a tolerância materna ao feto na gestação, assim como possíveis causas para a rejeição do embrião e complicações durante a gravidez.

\section{Aspectos Hormonais Relacionados à Ovulação, Fecundação e Implantação do Óvulo}

O ciclo ovulatório, ou ciclo menstrual, tem duração média de 28 dias e é coordenado por diversos hormônios como o GnRH; hormônios sexuais liberados pela hipófise (FSH e LH) após a estimulação do $\mathrm{GnRH}$; além de hormônios produzidos pelo ovário em resposta ao estímulo do LH e FSH (estrogênio e progesterona) (GUYTON; HALL, 2006).

Este ciclo pode ser dividido em duas fases: folicular e lútea. Na fase folicular ocorre o crescimento dos folículos ovarianos, processo estimulado pelo $\mathrm{LH}$ e FSH. Nesta etapa, a liberação hormonal é aumentada, com níveis mais elevados de FSH. Em consequência, há o amadurecimento de um único folículo, que começa a produzir estrogênio, que faz com que a secreção de FSH diminua por feedback. Quando o folículo se encontra completamente maduro ocorre a ovulação, processo que separa as duas fases e é caracterizado por um pico da concentração de LH. Após a expulsão do folículo há secreção de estrógeno e a progesterona. 
Caso não ocorra a fecundação, o óvulo degenera, a concentração destes hormônios diminui intensamente, e ocorre a menstruação (GUYTON; HALL, 2006).

Caso ocorra a fecundação, o corpo lúteo não se degenera mantendo as concentrações hormonais. Dessa forma o útero não exibe descamação, permitindo a implantação do óvulo e a sua permanência. À medida que ocorre a proliferação celular embrionária, começa a ser produzido HCG. Este hormônio tem várias funções durante a gravidez, dentre elas a de evitar a involução do corpo lúteo e consequente diminuição das concentrações de estrogênio e progesterona. Outra função importante do HCG é a promoção do crescimento uterino, em cerca de duas vezes (GUYTON; HALL, 2006).

Os hormônios da gravidez, além de promoverem o preparo do organismo da progenitora para fecundação e implantação do óvulo, também promovem a regulação imunitária (NEVES; MEDINA; DELGADO, 2007).

A progesterona induz uma resposta Th2 do organismo, que permite a não rejeição do feto. Este padrão de resposta ocasiona uma diminuição do número de células NK na periferia através da indução de citocinas Th2. Sua atuação também possibilita a indução de outros dois fatores, o fator de crescimento vascular endotelial(VEGF) e proteína-1 inflamatória de macrófagos (MIP-1 $\beta$ ), no endométrio. A progesterona ainda induz as células endometriais a produzirem IL-15 e prolactina, que regulam a proliferação das NK, a produção e a secreção de citocinas, o que consequentemente induz a imunomodulação local (DAHER; MATTAR, 2009).

Os glicocorticoides também têm papel fundamental na implantação e na manutenção da gestação. Além de exercerem influência sobre a regulação das células NK, eles ainda propiciam o aumento da produção de HCG e de progesterona, contribuindo para a diferenciação trofoblástica. Ocorre aumento da concentração do hormônio liberador de corticotrofina (CRH), diminuição da quantidade de linfócitos no útero, invasão do trofoblasto e um maior transporte de aminoácidos para o feto. $\mathrm{O}$ estrógeno e o hCG também influenciam o organismo materno a expressar a resposta Th2 (NEVES; MEDINA; DELGADO, 2007; PEREIRA et al., 2005).

\section{Embriogênese e Organogênese}

Ao ocorrer a fusão do gameta feminino com o gameta masculino, a célula resultante - o zigoto inicia um processo de divisão celular, originando células chamadas de blastômeros. Cerca de três dias após a fertilização, essas células passam a ser chamadas de mórula, que é responsável pela penetração na cavidade uterina. Após esse processo, ocorre a formação de uma cavidade entre os blastômeros centrais, chamada de blastocele, que é preenchida por líquido proveniente da cavidade uterina, responsável por separar os blastômeros em dois grupos celulares: trofoblasto e embrioblasto. O trofoblasto é uma camada externa que dará origem à parte fetal da placenta. Já o embrioblasto está localizado no polo embrionário e se desenvolverá, formando o embrião. Durante a fixação ao endométrio através do polo embrionário, o embrioblasto adquire uma cavidade e se torna um disco bilaminar, terminando esses processos em duas semanas após a fertilização. A cavidade formada será a cavidade amniótica, e as células voltadas para sua direção compõem o epiblasto, enquanto as células próximas a blastocele compõem o hipoblasto (NASSAR JÚNIOR; MIRANDA; MACÉA, 2002; MOORE; PERSAUD, 2004).

Durante o início da terceira semana de desenvolvimento, inicia-se um processo chamado de gastrulação. O epiblasto forma uma linha primitiva na região média do disco embrionário. A linha primitiva é responsável por dividir o disco embrionário bilaminado em três camadas germinativas: mesoderma, endoderma e ectoderma. O mesoderma se localiza entre o ectoderma e o endoderma. Essas três camadas resultantes serão responsáveis por formar os órgãos e tecidos do embrião (NASSAR JÚNIOR; MIRANDA; MACÉA, 2002). 
A partir do nó primitivo, formado pelas células do epiblasto da região cranial até a região caudal, células mesodérmicas indiferenciadas migram em direção cefálica, formando o canal notocordal. Este se desenvolve até uma região onde a camada endoderme e ectoderme, chamada de membrana orofaríngea, formará a boca do embrião. Parte do processo notocordal forma uma placa achatada chamada de placa notocordal, onde ocorre proliferação celular a partir da região cefálica dobrando-se sobre si mesma, formando a notocorda. A notocorda é responsável pela formação do sistema nervoso central, e ao seu redor irá se formar a coluna vertebral (NASSAR JÚNIOR; MIRANDA; MACÉA, 2002).

Ainda durante a terceira semana de desenvolvimento, a notocorda e o mesoderma induzem o ectoderma a se diferenciar em placa neural através de seu espessamento, e este passa a se chamar neuroectoderma. As pregas neurais, formadas a partir da placa neural, irão se fundir na região média, que seguirá para as regiões caudal e cranial para formar o tubo neural, que se destaca do ectoderma. Após a formação do tubo neural, algumas das células do neuroectoderma irão formar, bilateralmente ao lado do tubo neural, a crista neural. Estes processos, responsáveis pela formação do sistema nervoso central do embrião, são chamados de neurulação (NASSAR JÚNIOR; MIRANDA; MACÉA, 2002).

A partir da quarta até a oitava semana de gestação, inicia-se a organogênese, onde ocorre o desenvolvimento dos órgãos e tecidos do embrião, a partir das três camadas germinativas. Esse período pode ser dividido em três fases de desenvolvimento: o crescimento, onde ocorre a divisão celular; a morfogênese, onde ocorre o desenvolvimento dos órgãos e do corpo; e a diferenciação, onde ocorre a maturação dos tecidos e órgãos, que serão capazes de executar funções a partir desta maturação. Ao final da organogênese, o embrião passa a ter uma aparência humana (MOORE; PERSAUD, 2004).

\section{Células T e Gestação}

Durante a gestação, a resposta imune sofre uma transformação importante de modo a reduzir a atividade inflamatória, com alteração do pólo de células Th1 para Th2 (WEETMAN, 1999). Esta transformação do predomínio da resposta imune Th1 para Th2 é caracterizada pela diminuição da produção de citocinas, como IL-2 e interferon gama (INFy) e pelo aumento de IL-4 (MATTHIESEN et al., 1996; MARZI et al., 1996). Há uma redução da razão INF $\gamma /$ IL-4 — que é uma medida útil da razão CD4+Th1/Th2 - durante a gravidez e na fase inicial do período pósparto (REINHARD et al., 1998). Há, assim, alterações nas células $\mathrm{T}$ helper e supressoras de modo a permitir a aceitação do feto e a manutenção da gravidez (WATANABE et al., 1997).

No entanto, as células Th1 têm um papel essencial para a implantação e o desenvolvimento placentário. Parece assim ser fundamental o equilíbrio entre células Th1 e Th2, e que esta dicotomia Th1/Th2 pode auxiliar na compreensão dos microambientes de citocinas subjacentes a uma implantação bem sucedida (MELLOR; MUNN, 2000). O fator de necrose tumoral (TNF) é liberado pelas células natural killer uterinas (uNK) no começo da gestação. Observou-se seu papel na gestação em camundongos e sua relação com: 1 - proteção da mãe contra as células anormais fetais; 2 - restrição do trofoblasto à invasão da decídua materna; 3 - facilitação da remodelação do tecido requerido para acomodação do embrião; 4 - proteção contra transmissão de microorganismos da mãe para o feto (PARR et al.,1995).

A presença de IFN- $\gamma$ é necessária para a manutenção da decídua em humanos. IFN- $\gamma$ é secretado pelas uNK, sendo responsável pela remodelação dos vasos da decídua induzidos pela gravidez, e necessário para celularidade e integridade decidual. Além disso, receptores para IFN- $\gamma$ estão expressos em várias células que estão presentes nos locais de implantação (ZENCLUSSEN et al., 2002).

$\mathrm{Na}$ interface materno-fetal as citocinas do tipo Th2, que são secretadas não somente pelas células 
imunocompetentes, mas também por células da decídua e da placenta, parecem ser as responsáveis pelo sucesso na manutenção da gravidez (ZENCLUSSEN et al., 2002). Isso foi embasado na observação de que IL-4, IL-10 e IL-3 foram detectadas em níveis aumentados durante a gravidez normal em humanos e animais. Além disso, a administração de citocinas Th2 poderia prevenir o aborto em camundongos. Ao contrário, a produção excessiva de citocinas Th1 foi associada com perda gestacional, especialmente citocinas como IFN- $\gamma$, TNF, IL-1 e IL-2. Assim, a produção aumentada de citocinas $\mathrm{Th} 2$, em relação a produção diminuída de citocinas Th1, parece ser a razão para explicar a sobrevivência do feto no útero materno (ZENCLUSSEN et al., 2002).

O TGF-ß1 e TNF também estão envolvidas no crescimento e diferenciação do trofoblasto, na produção de outras citocinas com a IL-6 e IL-8, na expressão de moléculas de adesão, e na biogênese das metaloproteinases de matriz extracelular. Essas ações podem estar envolvidas no processo de trabalho de parto. A oxitocina, progesterona e hidrocortisona podem influenciar significativamente na expressão do mRNA e liberação tecidual de TGF-ß1 e TNF pelas membranas fetais na gestação a termo (ZICARI et al., 2002.). O TGF-ß1 é uma citocina imunossupressora que inibe a proliferação das células $\mathrm{T}$ e $\mathrm{B}$, a atividade citotóxica NK e a citotoxicidade das células T (LEE et al., 1987; ROOK et al., 1986). É secretado pelos linfócitos que sofrem apoptose e pelos macrófagos que fazem a fagocitose dos corpos apoptóticos (GERSTEIN, 1990). Numerosos estudos têm revelado o papel do TGF-ß1 na proteção da autoimunidade, documentando seus efeitos, em vários modelos experimentais de doenças autoimunes (BOIRIVANT et al., 1998; GRANDE, 1997), no desenvolvimento embrionário e na regulação imunológica da gravidez, inibição da produção de citocinas do tipo Th1 e promoção da diferenciação Th2 (CLARK et al., 1988; BRIDOUX et al., 1997). A regulação imune da gestação é complexa, estando envolvidos vários fatores hormonais na indução do estado Th2 da gravidez (ELENKOV et al., 2001). O papel de TGF- $\beta$ é ainda mais amplo, incluindo sua atuação na indução de células T reguladoras (CD4+CD25+) e Th17. A subpopulação celular Th17 caracteriza-se pela produção de IL-6 e IL17 e por sua participação na mediação da angiogênese e da inflamação (ALUVIHARE; KALLIKOURDIS; BETZ, 2004).

A progesterona, de forma particular, contribui para a imunomodulação associada à gravidez. (PICCINNI et al., 1995; BROSENS, 2006). Os efeitos imunológicos da progesterona são mediados parcialmente, por uma fração de $34 \mathrm{kDa}$, denominada fator bloqueador induzido pela progesterona (PIBF) (SZEKERESBARTHO et al., 1985). Este fator, produzido pelas células $\mathrm{T}$ ativadas expostas à progesterona, afeta os macrófagos e as células NK placentárias e, também, as células circulantes (FAUST et al., 1999). O PIBF é dotado de propriedades imunomoduladoras, tais como a capacidade de regular a expressão de perforinas pelas células NK (SZEKERES-BARTHO et al., 1989). Também afeta o balanço Th1/Th2 através do aumento da produção de IL-3, IL-4 e IL-10 e da diminuição da produção de IL-12 nos linfócitos e macrófagos (SZEKERES-BARTHO; WEGMANN, 1996). Os estrogênios têm um efeito similar no balanço Th1/Th2 (DEALTRY; O'FARREL; FERNANDEZ, 2000). A progesterona, através da sua capacidade de estimular a síntese de citocinas Th2, promove a produção de HCG no trofoblasto (LASKARIN et al., 1999). O HCG, subsequentemente, estimula a formação de progesterona, criando, assim, um mecanismo de feedback positivo (SAITO, 2000).

Todos estes mecanismos contribuem para a promoção Th2, com aumento significativo da produção de IL-12 e de TNF- $\alpha$ no terceiro trimestre da gravidez. (ELENKOV et al., 2001). No período pós-parto as alterações imunes associadas à regulação diferencial das respostas Th1 e Th2 favorecem a resposta Th1, que está associada à recidiva de várias doenças auto-imunes (ROCHESTER; DAVIES, 2005; PREMAWARDHANA et al., 2004).

Outro mecanismo descrito na tolerância maternofetal é o catabolismo do triptofano por células 
dendríticas (DCs). A degradação do triptofano pela enzima indoleamina 2,3 dioxigenase (IDO) leva à supressão de respostas de células T (MELLOR et al., 2001; MUNN et al., 1998). Isto sugere que a atividade da IDO é um mecanismo chave envolvido na tolerância materno-fetal em camundongos. Embora os estudos em seres humanos sejam limitados, IDO foi detectada em macrófagos deciduais humanos (KUDO et al., 2001) e em explantes vilosos placentários demonstrando ser capaz de inibir as respostas das células T. Curiosamente, a expressão de IDO também pode ser influenciada pelo antígeno 4 do linfócito T citotóxico (CTLA-4), uma molécula expressa por células $\mathrm{T}$ regulatórias (Treg) (GROHMANN et al., 2002; FALLARINO et al., 2003). Estudos têm demonstrado que a CTLA-4 solúvel ou Treg expressando CTLA-4 pode estimular o aumento da regulação da IDO e o catabolismo do triptofano (FALLARINO et al., 2003).

Observa-se aumento rápido de células Treg circulantes durante o início da gravidez, com um pico durante o segundo trimestre, quando a invasão trofoblástica da decídua materna é máxima (PIJNENBORG et al., 1983). O declínio de células Treg pós-parto também é consistente com a retirada do estímulo imunológico do enxerto. Esta população de células CD25+ pode inibir a indução de proliferação de linfócitos e o contato célula-célula é necessário para que as Tregs medeiem a imunossupressão (SOMERSET et al., 2004).

Os mecanismos pelos quais as Tregs possam modular as respostas imunológicas durante a gravidez ainda devem ser mais estudados. No entanto, estudos recentes em ratos demonstraram que a tolerância a aloantígenos é essencial para o sucesso da gravidez (SOMERSET et al., 2004).

\section{Expressão de HLA-G}

Existem duas classes de HLA, I e II. Os genes de classe I são subdivididos em classe Ia, que inclui HLA-A, - B e - C, e de classe Ib, que inclui HLA-E, - F e -G. HLA de classe II é composto pelo HLA-D (HUNT et al., 2005). Portanto, o HLA-G é uma molécula não clássica de HLA que se distingue dos outros antígenos clássicos de classe I por ter uma distribuição restrita a tecidos específicos e polimorfismo reduzido. Existem seis isoformas: quatro ligadas a membrana (G1 a G4) e duas formas solúveis (G5 e G6) (VICENTE et al., 2000).

A expressão de HLA-G é característica na gravidez. A presença de HLA-G na placenta e no citotrofoblasto extraviloso tem sido demonstrada em estudos experimentais, que ainda revelam uma maior intensidade no primeiro trimestre, decrescendo com o decorrer da gestação (DAHER; MATTAR, 2009). A expressão do HLA-G é responsável pela inibição das células NK, impedindo a sua ativação contra o embrião. Simultaneamente, a produção local de IL10, além de aumentar a expressão de HLA-G, dirige a resposta imunitária para uma resposta do tipo Th2. A existência de HLA-G solúvel pode manter a tolerância a nível sistêmico (VICENTE et al., 2000).

Estes antígenos de membrana determinam e coordenam muitas funções imunológicas promovendo a interação com diferentes tipos celulares. Dentre suas funções estão incluídas a modulação do padrão de citocinas e fatores de crescimento produzidos, a inibição da atividade lítica de células NK e apresentação de peptídeos virais para células T. Além disso, influenciam o processo de apoptose de células $\mathrm{T}$ ativadas. Assim, os antígenos HLA-G desenvolvem um papel central na defesa contra infecções e no desencadeamento e manutenção de tolerância imunológica materno-fetal. Antígenos HLA-G podem ser encontrados no soro, líquido amniótico, sangue de cordão e em sobrenadante de cultura de células trofoblásticas em sua forma solúvel. A identificação de HLA-G solúvel é considerada um parâmetro de bom prognóstico da gestação devido a sua importância na modulação da resposta materno-fetal. Por outro lado, a ausência ou expressão reduzida do HLA-G parece estar associada a intercorrências obstétricas como falhas de implantação, aborto espontâneo de repetição e até mesmo, pré-eclâmpsia (DAHER; MATTAR, 2009). A disfunção de células NK pode estar ligada a secreção 
anormal de células T, de IL-12 e/ou ao reconhecimento anormal pelo HLA-G, e assim provocar alteração na regulação da angiogênese (CHAOUAT et al., 2003).

A expressão de HLA-G pode ser regulada em nível da transcrição, tradução e transporte para a superfície celular dependendo do tipo de célula e tempo de gestação. No primeiro trimestre, o HLA-G é altamente transcrito no citotrofoblasto extraviloso, traduzido e exportado para a membrana celular. A transcrição nesta subpopulação de células do trofoblasto declina com o avanço da gestação (LE BOUTEILLER; MALLET, 1997).

A hipótese de que o HLA-G atua como o maior inibidor de toxicidade NK na interface materno-fetal continua consistente e experimentos com anticorpos específicos HLA-G mostram que células do trofoblasto inibem a morte das células NK mediada na ausência de HLA-E. Estes efeitos podem ser mediados através do killer inhibitory receptors (KIR) (HUNT et al., 2005).

São exemplos de tolerância celular na interface materno-fetal, com consequências benéficas para o feto a ausência de moléculas clássicas de MHC na superfície do trofoblasto, e o reconhecimento de moléculas não clássicas de HLA-G por receptores KIR nas células uterinas NK. Verificou-se que a ligação de células do trofoblasto a receptores inibitórios das células NK, os KIRs, resultava em um efeito protetor. Estes receptores veiculam sinais inibitórios, que inibem a ativação de células NK. Durante a gravidez, mesmo o sistema imunitário materno estando ativo e funcional, existem diversos mecanismos subjacentes à tolerância materna do feto que permitem a implantação e a gestação bem sucedida. Pode-se citar como mecanismos essenciais para a tolerância da mãe ao feto ainda: a expressão de moléculas de HLA-G, HLA-E e HLA-C nas células do trofoblasto, a expressão de proteínas reguladoras do complemento, a regulação do recrutamento de leucócitos e proliferação celular na interface maternofetal e a supressão de linfócitos Th1 na decídua. (SARAFANA et al., 2007).

O principal tecido que interage com o sistema imune materno a partir da implantação é constituído pelas células trofoblásticas, as quais passam a representar a interface materno-embrionária. Essas células têm expressão diferenciada de moléculas HLA, responsáveis pela identificação do que é "próprio" e "não próprio" no organismo de cada indivíduo. Além disso, elas têm um potencial peculiar de resposta às citocinas presentes no meio. O comportamento de "tolerância imunológica" aos tecidos embrionários se deve a essas características, o que é fundamental para o desenvolvimento de uma gestação normal.

O citotrofoblasto extraviloso expressa o HLA-G de forma limitada à placenta e células epiteliais tímicas. Considerando-se que nenhuma célula trofoblástica expressa HLA de classe II essas células não são capazes de estimular diretamente as células Th para o disparo de reações imunológicas mais complexas. Dessa forma, sem qualquer expressão de moléculas HLA de classe I e II, as células trofoblásticas vilosas não podem funcionar como alvo de respostas citotóxicas mediadas por células $\mathrm{T}$ durante uma gestação normal (MICHELON et al., 2006).

\section{Antígenos de Histocompatibilidade Menor}

Os antígenos de histocompatibilidade menor (mHAgs) fazem parte dos antígenos fetais. São proteínas funcionais que podem desencadear uma resposta imunológica por diferença alélica entre pessoas, (GOULMY, 2006) e dentre suas variantes, podendo ser um polimorfismo de um único nucleotídeo (SNP), ou até estar presente no cromossomo Y (DEN HAAN et al., 1998; OFRAN et al., 2010). O papel dos mHAgs em provocar uma resposta imunológica foi demonstrado por estudos de transplantes. Desde estas descobertas, mais de cinquenta mHAgs únicos derivados de 43 genes foram encontrados (LINSCHEID; PETROFF, 2013). A participação dos mHAgs na gravidez foi considerada por vários pesquisadores como o motivo para rejeição de enxertos, após observarem que doadoras sem gravidez prévia ou doadores do sexo masculino são menos susceptíveis a provocar rejeição de enxerto pelo paciente transplantado do que doadoras que são 
mães (LOREN et al., 2006; RANDOLPH et al., 2004; TAKAMI et al., 2004).

Os mHAgs são reconhecidos por células Tatravés de sua apresentação pelo MHC de classe I ou II (OFRAN et al., 2010). Acredita-se que esse reconhecimento ocorra durante a liberação dos restos placentários da mãe contendo mHAgs fetais na corrente sanguínea materna, onde seriam processados e fagocitados por células dendríticas e apresentados para células TCD8+, gerando uma resposta imunológica materna para o feto (ERLEBACHER et al., 2007).

Existem vários tipos de mHAgs (LINSCHEID; PETROFF, 2013), e o antígeno de histocompatibilidade 1 (HA-1) é um dos mais estudados, podendo ser encontrado em células de Hofbauer (células localizadas no estroma das vilosidades coriônicas que secretam citocinas para o crescimento e diferenciação do trofoblasto) (ALVES et al., 2007), e no trofoblasto, na placenta humana (HOLLAND et al., 2012). O peptídeo antigênico do HA-1 resulta de uma única diferença nucleotídica entre o peptídeo não imunogênico e o peptídeo imunogênico (DEN HAAN et al., 1998) que aumenta a afinidade de ligação do peptídeo HA-1 a um peptídeo específico HLA-A*0201 ligado em células apresentadoras de antígeno (APC) (NICHOLLS et al., 2009), podendo levar a um reconhecimento por células $\mathrm{T}$ específicas para HLA-A*0201. O reconhecimento do antígeno HA-1 pode ocorrer em situações como em casos de rejeição de enxerto ou em casos de gravidez (LINSCHEID; PETROFF, 2013). No caso da gravidez, a presença de células T específicas para HA-1 no sangue materno após a gravidez indica que essas células $\mathrm{T}$ maternas podem reconhecer o HA-1 imunogênico fetal (VERDIJK et al., 2004). O contato entre o sinciciotrofoblasto e o fornecimento de sangue materno na superfície da placenta pode gerar uma resposta imune materna para mHAgs fetais (PETROFF, 2011). Nestes casos, as células $\mathrm{T}$ específicas ao antígeno são provenientes de um indivíduo sem o alelo HA-1 imunogênico. A probabilidade de que dois indivíduos possuirão HA-1 diferentes, e que o indivíduo com o HA-1 não imunogênico terá o MHC para apresentar o peptídeo imunogênico e gerar uma resposta imune, é de cerca de 12\% (LINSCHEID; PETROFF, 2013).

Foi demonstrado, através de estudos em camundongos, que outro tipo de mHAg, o antígeno fetal endógeno $(\mathrm{H}-\mathrm{Y})$, pode induzir células TCD4+ e TCD8+ a desenvolverem uma resposta imune (JAMES et al., 2003). Outros estudos em camundongos demonstram que antígenos paternos podem ser encontrados no sêmen. Sendo assim, a apresentação de antígenos fetais para células $\mathrm{T}$ maternas pode começar durante a relação sexual entre os progenitores (ERLEBACHER et al., 2007; MOLDENHAUER et al., 2009). Recentemente, um estudo demonstrou que durante a gravidez humana com um feto do sexo masculino pode-se encontrar células TCD8+ específicas para H-Y no sangue materno (LISSAUER et al., 2012).

Evidências epidemiológicas sugerem que o reconhecimento de mHAgs fetais pode estar relacionado ao aborto recorrente secundário, principalmente se no primeiro aborto o feto for do sexo masculino (CHRISTIANSEN; STEFFENSEN; NIELSEN, 2010; NIELSEN et al., 2009; OOI; RUSSEL; O’DONOGHUE, 2011).

\section{O Sinciciotrofoblasto}

O sinciciotrofoblasto forma uma camada contínua em torno das vilosidades coriônicas da placenta humana, e representa uma grande área de tecido fetal em contato com o sangue materno. As células do sinciciotrofoblasto não expressam moléculas de HLA e são responsáveis tanto pela nutrição do embrião, quanto pela produção de HCG e progesterona. Além disso, há a produção de IDO, que leva à inibição da resposta local de células T por diminuir a concentração de triptofano (KAMIMURA et al., 1991).

Anticorpos maternos ligam-se às moléculas de HLA paternas presentes nos tecidos embrionários, funcionando como proteção à resposta citotóxica materna contra o embrião (MICHELON et al., 2006). Estes anticorpos não ativam o complemento 
localmente e por isso não desencadeiam uma resposta imune efetiva para a eliminação dos antígenos. Isto ocorre, pois há uma glicosilação de uma das regiões Fab da molécula do anticorpo $\mathrm{IgG}$, resultando em conformação assimétrica. Acredita-se que a finalidade destes anticorpos seja recobrir a interface maternofetal via HLA-G e com isso bloquear a citotoxicidade local (GUTIERREZ et al., 2005).

Anticorpos anti-HLA classe I, classe II e anti-HLA-G podem ser identificados com maior frequência em multíparas. Existem evidências de que estes anticorpos favoreçam a gestação, protegendo as células fetais da ação de células citotóxicas maternas (HVIID, 2006). Desta forma, as moléculas HLA-G atuam como o estímulo paterno para a produção de anticorpos bloqueadores que protegerão o embrião e permitirão o desenvolvimento dos tecidos placentários.

\section{Anticorpos e Perda Gestacional}

A perda gestacional é uma das complicações mais frequentes da gestação, e ocorre principalmente durante o primeiro trimestre. Dentre as diversas causas da perda gestacional está a produção de auto anticorpos, produzidos sumariamente por uma falha na tolerância imunológica aos antígenos próprios (principalmente maternos), alterando a relação materno-fetal. Os principais anticorpos relacionados à perda gestacional são os anticorpos antifosfolípides, presentes em cerca de $10 \%$ das mulheres com perda fetal de repetição.

A síndrome de anticorpos antifosfolípides (SAF) se caracteriza pela presença de auto anticorpos que reagem contra fosfolipídios de membrana carregados negativamente, levando a episódios de anemia hemolítica, tromboses arteriais e venosas, e trombocitopenia (CHRISTIANSEN, 2006). Os principais anticorpos antifosfolípides são o anticoagulante lúpico (LAC) e o anticorpo anticardiolipina(ACA).Aação desses anticorpos se dá contra antígenos endoteliais, podendo levar à vasculite decidual. Esta vasculite, associada ao mecanismo de hipercoagulabilidade promovido pelos anticorpos antifosfolípides, pode desencadear alterações na vascularização para placenta e feto (FERGUSON et al., 2007). Existem ainda outros anticorpos dirigidos contra a fosfatidilserina, fosfatidiletanolamina, fosfatidilinositol, fosfatidilglicerol, fosfatidilcolina e ácido fosfórico, porém a frequência com que ocorrem é bastante inferior (FIGUEIRÓ-FILHO et al., 2005).

Há também a produção de anticorpos antiespermatozoides (AAE), que podem influenciar no desenvolvimento dos gametas e na fertilização. O aparecimento destes anticorpos aparenta estar associado à diminuição de fertilidade em ambos os sexos, pois há indicações de que estes anticorpos afetem a maturação do espermatozoide e a qualidade do sêmen (CHOUDHURY; KNAPP, 2001).

\section{TGF-B}

TGF- $ß$ representa uma superfamília de proteínas envolvidas no controle da proliferação e diferenciação celular, imunorregulação, angiogênese e regulação da matriz extracelular (ATTISANO et al., 1994), além de possuir a capacidade de induzir apoptose em diversos tipos de células (MOULTON, 1994). Em mamíferos há a presença de três membros da superfamília do TGF- ß: TGF-ß1, TGF-ß2 e TGF-ß3.

Quando produzida pelas células NK, o TGF-ß inibe a proliferação e diferenciação do trofoblasto (DAS et al., 2002). Esta citocina também é produzida por macrófagos, juntamente com TNF- $\alpha$ e fatores estimuladores de colônia (REDLINE et al., 1990), constituindo importante papel na invasão do trofoblasto e implantação, e consequente sucesso da gravidez.

O papel de regulador negativo do TGF- $\beta$ é importante na gestação, uma vez que contribui com efeitos imunossupressores na mãe, auxiliando na não rejeição do feto(GORCZYNSKI et al., 2002). Durante a gestação o TGF- $ß$ atua inibindo a proliferação e diferenciação de linfócitos e controlando a ativação de outros leucócitos (LETTERIO; ROBERTS, 1998). 


\section{Conclusão}

Para que uma gravidez ocorra, são necessários diversos mecanismos ealterações no organismo da mãe, principalmente em seu sistema imunológico. Caso não ocorra essa modulação o feto pode ser rejeitado. Tem sido verificado que a produção de mHAgs na gravidez pode ser uma das causas de rejeição. Outro mecanismo de rejeição e perda fetal é a produção de anticorpos contra espermatozoide o contra o feto. Alguns hormônios são de extrema importância para que a mãe tolere o feto durante toda a gestação. Pode-se citar o HCG, progesterona, estrógeno, glicocorticóides, entre outros, que participam da modulação da imunidade.

O balanço Th1/Th2 e supressão das células NK (mantida pelo HLA-G e TGF- $\beta$ 1, principalmente) também é importante para manutenção da gestação. O HLA-G pode ser encontrado na placenta e no citotrofoblasto extraviloso sendo bom prognóstico para a gestação. Durante a gestação o TGF- $ß$ atua inibindo a proliferação e diferenciação de linfócitos e controlando a ativação de outros leucócitos. Somente com o equilíbrio e coordenação imunológica e hormonal dos mecanismos descritos é possível ocorrer uma gestação normal, onde esses fatores contribuem para a tolerância da mãe ao feto.

\section{Referências}

ALUVIHARE, V. R.; KALLIKOURDIS, M.; BETZ, A. G. Regulatory T cells mediate maternal tolerance to the fetus. Nature Immunology, New York, v. 5, n. 3, p. 26671, 2004.

ALVES, C.;VEIGA, S.;TORALLES, M. B. P.;LOPES, A. C. V.O papel do complexo principal de histocompatibilidade na fisiologia da gravidez e na patogênese de complicações obstétricas. Revista Brasileira de Saúde Materno Infantil, Recife, v. 7, n. 4, p. 357-363, 2007.

ATTISANO, L.; WRANA, J. L.; LOPEZ-CASILLAS, F.; MASSAGUE, J. TGF-beta receptor sandactions. Biochimica et Biophysica Acta, Amsterdam, v. 1222, p. 71-80, 1994.
BOIRIVANT, M.; FUSS, I. J.; CHU, A.; STROBER, W. Oxazolone colitis: a murine model of T helper cell type 2 colitis treatable with autoantibodies to interleukin 4. The Journal of Experimental Medicine, New York, v. 188, n. 10, p. 1929-1939, 1998.

BRIDOUX, F.; BADOU, A.; SAOUDI, A.; BERNARD, I.; DRUET, E.; PASQUIER, R.; DRUET, P.; PELLETIER, L. Transforming growth factor $\beta$ (TGFß)-dependent inhibition of helper cell 2 (Th2)- induced autoimmunity by self-major histocompatibility complex (MHC) class II-specific, regulatory CD4+ T cell lines. The Journal of Experimental Medicine, New York, v. 185, n. 10, p. 1769-75, 1997.

BROSENS, G. B. Death or survival: progesteronedependent cell fate decisions in the human endometrial stroma. Journal of Molecular Endocrinology, Bristol, v. 36, n. 3, p. 389-98, 2006.

CHAOUAT, G.; LEDEE-BATAILLE, N.; ZOURBAS, S.; DUBANCHET, S.; SANDRA, O.; MARTAL, J.; OSTOJOJIC, S.; FRYDMAN, R. Implantation: can immunological parameters of implantation failure be of interest for preeclampsia? Journal of Reproductive Immunology, Amsterdam, v. 59, n. 2, p. 205-217, 2003.

CHOUDHURY, S. R.; KNAPP, L. A. Human reproductive failure I: immunological factors. Human Reproduction Update, Oxford, v. 7, n. 2, p. 135-60, 2001.

CHRISTIANSEN, O. B. Evidence-based investigations and treatments of recurrent pregnancy loss. Current Opinion in Obstetrics \& Gynecology, London, v.18, n. 3, p. 304-312, 2006.

CHRISTIANSEN, O.B.; STEFFENSEN, R.; NIELSEN, H. S.The impact of anti-HY responses on outcome in current and subsequent pregnancies of patients with recurrent pregnancy losses. Journal of Reproductive Immunology, Amsterdam, v. 85, n. 1, p. 9-14, 2010.

CLARK, D. A.; FALBO, M.; ROWLEY, R. B.; BANWATT, D.; STEDRONSKA-CLARK, J. Active suppression of host-vs-graft reaction in pregnant mice. IX. Soluble suppressor activity obtained from allopregnant mouse decidua that blocks the cytolytic effector response to IL-2 is related to transforming growth factor ß. Journal of Reproductive Immunology, Amsterdam, v. 141, p. 3833-40, 1988. 
DAHER, S.; MATTAR, R. Gestação: um fenômeno imunológico? Revista Brasileira de Alergia e Imunopatologia, São Paulo, v. 32, n. 2, p. 63-67, 2009.

DAS, C.; KUMAR, V.S.; GUPTA, S.; KUMAR, S. Network of cytokines, integrins and hormones in human trophoblast cells. Journal of Reproductive Immunology, Amsterdam, v. 53, n. 1-2, p. 257-268, 2002.

DEALTRY, G. B.; O'FARREL, M. K.; FERNANDEZ, N. The Th2 cytokine environment of the placenta. International Archives of Allergy and Immunology, New York, v. 123, p. 107-19, 2000.

DEN HAAN, J. M.; MEADOWS, L. M.; WANG, W.; POOL, J.; BLOKLAND, E.; BISHOP, T. L.; REINHARDUS, C.; SHABANOWITZ, J.; OFFRINGA, R.; HUNT, D. F.; ENGELHARD, V. H.; GOULMY, E. The minor histocompatibility antigen HA-1: a diallelic gene with a single amino acid polymorphism. Science, New York, v. 279, p.10541057, 1998.

ELENKOV, I. J.; WILDER, R. L.; BALAKOV, V. K.; LINK, A. A.; DIMITROY, M. A.;FISHER, S.; CRANE, M.; KANIK, K. S.; CHROUSOS, G. P. IL-12, TNF- $\gamma$, and hormonal changes during late pregnancy and early postpartum: implications for autoimmune disease activity during these times. The Journal of clinical endocrinology and metabolism, Springfield, v. 86, n. 10, p. 4933-4938, 2001.

ERLEBACHER, A.; VENCATO, D.; PRICE, K.A.; ZHANG, D.; GLIMCHER, L. H. Constraints in antigen presentation severely restrict $\mathrm{T}$ cell recognition of the allogeneic fetus. The Journal of Clinical Investigation, New Haven, v. 117, n. 15, p.1399-1411, 2007.

FALLARINO, F.; GROHMANN, U.; HWANG, K. W. ORABONA, C.; VACCA, C.; BIANCHI, R.; BELLADONNA, M. L.; FIORETTI, M. C.;ALEGRE, M. L.; PUCCETTI, P. Modulation of tryptophan catabolism by regulatory T cells. Nature Immunology, New York, v. 4, n. 12, p. 1206-1212, 2003.

FAUST, Z.; LASKARIN, G.; RUKAVINA, D.; SZEKERES-BARTHO, J. Progesterone-induced blocking factor inhibits degranulation of natural killer cells. American Journal of Reproductive Immunology, New York, v. 42, n. 2, p. 71-75, 1999.
FERGUSON, E. J.; LAIRD, J.; TAIT, C.; WALKER, I. Anticardiolipin antibodies and outcome of pregnancy - a retrospective 3 year study. Journal of Thrombosis and Haemostasis, North Carolina, v. 5, supl. 2, p. 447, 2007.

FIGUEIRÓ-FILHO, E. A.; LOPES, A. H. A.; SENEFONTE, F. R. A.; DUARTE, G. Lúpus eritematoso sistêmico e gestação. Femina, Rio de Janeiro, v. 33, p. 451-61, 2005.

GERSTEIN, H. C. How common is postpartum thyroiditis? A methodologic overview of the literature. Archives of Internal Medicine, Chicago, v. 150, n. 7, p. 1397-1400, 1990.

GORCZYNSKI, R. M.; HADIDI, S.; YU, G.; CLARK, D. A. The same immunoregulatory molecules contribute to successful pregnancy and transplantation. American Journal of Reproductive Immunology, New York, v. 48, n. 1, p. 18-26, 2002.

GOULMY, E. Minor histocompatibility antigens: from transplantation problems to therapy of cancer. Human Immunology, New York, v. 67, n. 6, p. 433438, 2006.

GRANDE, J. P. Role of transforming growth factor- $\beta$ in tissue injury and repair. Proceedings of the Society for Experimental Biology and Medicine, New York, v. 214, n. 1, p. 27-40, 1997.

GROHMANN, U.; ORABONA, C.; FALLARINO, F.; VACCA, C.; CALCINARO, F.; FALORNI, A.; CANDELORO, P.; BELLADONNA, M. L.; BIANCHI, R.; FIORETTI, M. C.; PUCCETTI, P. CTLA-4-Ig regulates tryptophan catabolism in vivo. Nature Immunology, New York, v. 3, n. 11, p. 1097-101, 2002.

GUTIERREZ, G.; GENTILE, T.; MIRANDA, S.; MARGNI, R.A. Asymmetric antibodies: a protective arm in pregnancy. Chemical Immunology and Allergy, Basel, v. 89, p. 158-168, 2005.

GUYTON, A. C.; HALL, J. E. Tratado de fisiologia médica. 11. ed. Rio de Janeiro: Elsevier, 2006. 
HOLLAND, O. J.; LINSCHEID, C.; HODES, H. C.; NAUSER, T. L.; GILLIAM, M.; STONE, P.; CHANLEY, L. W.; PETROFF, M. G. Minor histocompatibility antigens are expressed in syncytiotrophoblast and trophoblast debris: implications for maternal alloreactivity to the fetus. The American Journal of Pathology, Philadelphia, v. 180, n. 1, p. 256266, 2012.

HUNT, J. S.; PETROFF, M. G.; MCINTIRE, R. H.; OBER, C. HLA-G and immune tolerance in pregnancy. The FASEB Journal, v. 19, pg 681, 2005.

HVIID, T. V. HLA-G in human reproduction: aspects of genetics, function and pregnancy complications. Human Reproduction Update, Oxford, v. 12, n. 3, p. 209-32, 2006.

JAMES, E.; CHAI, J. G.; DEWCHAND, H.; MACCHIARULO, E.; DAZZI, F.; SIMPSON, E. Multiparity induces priming to male-specific minor histocompatibility antigen, HY, in mice and humans. Blood, New York, v. 102, n. 1, p. 388-393, 2003.

KAMIMURA, S.; EGUCHI, K.; YONEZAWA, M.; SEKIBA, L. Localization and developmental change of indoleamine 2,3-dioxygenase activity in thehuman placenta. Acta medica Okayama, Okayama, v. 45, n. 3, p. 135-139, 1991.

KUDO, Y.; BOYD, C.A.; SARGENT, I. L.; REDMAN, C. W. Tryptophan degradation by human placental indoleamine 2,3-dioxygenase regulates lymphocyte proliferation. JPhysiol, v. 535: 207-15, 2001.

LASKARIN, G.; STRBO, N.; SOTOSEK, V.; RUKAVINA, D.; FAUST, Z.; SZEKERES-BARTHO, J.; PODACK, E. R. Progesterone directly and indirectly affects perforin expression in cytolytic cells. American journal of reproductive immunology, New York, v. 42, n. 5, p. 312-320, 1999.

LE BOUTEILlER, P.; MALLET, V. HLA-G and pregnancy. Reviews of Reproduction, Colchester, v. 2, n. 1, p. 7-13, 1997.

LEE, G. L.; ELLINGSWORTH, L. R.; GILLIS, S.; WALL, R.; KINCADE, P. W. $ß$ Transforming growth factors are potential regulators of $\mathrm{B}$ lymphopoiesis. The Journal of Experimental Medicine, New York, v. 166, n. 5, p. 1290-1299, 1987.
LETTERIO, J. J.; ROBERTS, A. B. Regulation of immune responses by TGF-beta. Annual Review of Immunology, Palo Alto, v. 16, p. 137-61, 1998.

LINSCHEID, C.; PETROFF, M. G. Minor histocompatibility antigens and the maternal immune response to the fetus during pregnancy. American Journal of Reproductive Immunology, New York, v. 69, n. 4, p. 304-314, 2013.

LISSAUER, D.; PIPER, K.; GOODYEAR, O.; KILBY, M. D.; MOSS, P. A. Fetalspecific CD8+ cytotoxic $\mathrm{T}$ cell responses develop during normal human pregnancy and exhibit broad functional capacity. Journal of Immunology, Baltimore, v. 189, n, 2, p.1072-1080, 2012.

LOREN, A. W.; BUNIN, G. R.; BOUNDREAU, C.; CHAMPLIN, R. E.; CNAAN, A.; HOROWITZ, M. M.; LOBERIZA, F. R.; PORTER, D. L. Impact of donor and recipient sex and parity on outcomes of HLA-identical sibling allogeneic hematopoietic stem cell transplantation. Biology of Blood and Marrow Transplantation, Charlottesville, v. 12, n. 7, p. 758769, 2006.

MARZI, M.; VIGANO, A.; TRABATTONI, D.; VILLA, M. L.; SALVAGGIO, A.; CLERICI, E.; CLERICI, M. Characterization of type 1 and type 2 cytokine production profile in physiologic and pathologic human pregnancy. Clinical and Experimental Immunology, Oxford, v. 106, n. 1, p. 127-133, 1996.

MATTHIESEN，L.; BERG，G.; EMERUDH，J.; HAKANSSON, L. Lymphocyte subsetsand mitogen stimulation of blood lymphocytes in normal pregnancy. American Journal of Reproductive Immunology, New York, v. 35, p. 70-79, 1996.

MELLOR, A. L.; MUNN, D. H. Immunology at the maternal fetal interface: lessons for $\mathrm{T}$ cell tolerance and suppression. Annual Review of Immunology, Palo alto, v. 18, p. 367-391, 2000.

MELLOR, A. L.; SIVAKUMAR, J.; CHANDLER, P.; SMITH, K.; MOLINA, H.; MAO, D.; MUNN, D $\mathrm{H}$. Prevention of T cell-driven complement activation and inflammation by tryptophan catabolism during pregnancy. Nature Immunology, New York, v. 2, n. 1, p. 64-68, 2001. 
MICHELON, T.; SILVEIRA, J. G.; GRAUDENZ, M.; NEUMANN, J. Imunologia da gestação. Revista da AMRIGS, Porto Alegre, v. 50, n. 2, p. 145-151, abr./ jun. 2006.

MOLDENHAUER, L. M.; DIENER, K. R.; THRING, D. M.; BROWN, M. P.; HAYBALL, J. D.; ROBERTSON, S. A. Cross-presentation of male seminal fluid antigens elicits $\mathrm{T}$ cell activation to initiate the female immune response to pregnancy. Journal of Immunology, Baltimore, v. 182, p. 8080-8093, 2009.

MOORE, K. L.; PERSAUD, T. V. N. Embriologia clínica. 7. ed. Rio de Janeiro: Elsevier, 2004.

MOULTON, B. C. Transformin growth factor-beta stimulates endometrial stromalapoptosis in vitro. Endocrinology, Los Angeles, v. 134, n. 3, p. $1055-$ 1060, 1994.

MUNN, D. H.; ZHOU, M.; ATTWOOD, J. T. BONDAREV, I.; CONWAY, S. J.; MARSHALL, B.; BROWN, C.; MELLOR, A. L. Prevention of allogeneic fetal rejection by tryptophan catabolism. Science, New York, v. 281, p. 1191-1193, 1998.

NASSAR JÚNIOR, A. P.; MIRANDA, D.; MACÉA, J. R. Uma revisão sobre as células da crista neural Parte I: histórico e embriogênese. Arquivos Médicos, São Paulo, v. 47, n. 1, 2002.

NEVES, C.; MEDINA, J. L.; DELGADO, J. L. Alterações Endócrinas e Imuno-modulação na Gravidez. Arquivos de Medicina, Porto, v. 21, n. 5-6, 2007.

NICHOLLS, S.; PIPER, K. P.; MOHAMMED, F.; DAFFORN, T. R.; TENZER, S.; SALIM, M.; MAHENDRA, P.; CRADDOCK, C.;VAN ENDERT, P.; SCHILD, H.; COBBOLD, M.; ENGELHARD, V. H.; MOSS, P. A.; WILLCOX, B. E. Secondary anchor polymorphism in the HA-1 minor histocompatibility antigen critically affects MHC stability and TCR recognition. Proceedings of the National Academy of Sciences of the United States of America, Washington, v. 106, n. 10, p. 3889-3894, 2009.
NIELSEN, H. S.; STEFFENSEN, R.; VARMING, K.; VAN HALTEREN, A. G.; SPIERINGS, E.; RYDER, L. P.; GOULMY, E.; CHRISTIANSEN, O. B. Association of HY restricting HLA class II alleles with pregnancy outcome in patients with recurrent miscarriage subsequent to a firstborn boy. Human molecular genetics, Oxford, v. 18, n. 9, p. 1684-1691, 2009.

OFRAN, Y.; KIM, H. T.; BRUSIC, V.; BLAKE, L.; MANDRELL, M.;WU,C. J.; SARANTOPOULOS, S.; BELLUCCI, R.; KESKIN, D. B.; SOIFFER, R. J.; ANTIN, J. H.; RITZ, J. Diverse patterns of T-cell response against multiple newly identified human Y chromosome-encoded minor histocompatibility epitopes. Clinical Cancer Research, Denville, v. 16, n. 5, p. 1642-1651, 2010.

OOI, P. V.; RUSSELL, N.; O’DONOGHUE, K. Secondary recurrent miscarriage is associated with previous male birth. Journal of Reproductive Immunology, Amsterdam, v. 88, n. 1, p. 38-41, 2011.

PARR, E. L.; CHEN, H. L.; PARR, M. B.; HUNT, J. S. Synthesis and granular localization of tumor necrosis factor-alpha in activated NK cells in the pregnant mouse uterus. Journal of Reproductive Immunology, Amsterdam, v. 28, n. 1, p. 31-40, 1995.

PEREIRA, A. C.; JESÚS, N. R.; LAGE, L. V.; LEVY, R. A. Imunidade na gestação normal e na paciente com lúpus eritematoso sistêmico (LES). Revista Brasileira de Reumatologia, São Paulo, v. 45, n. 3, p. 134-140, 2005.

PETROFF, M. G. Review: fetal antigens - identity, origins, and influences on the maternal immune system. Placenta, London, v. 32, supl. 2, p. S176-S181, 2011.

PICCINNI, M. P.; GIUDIZI, M. G.; BIAGIOTTI, R.; BELONI, L.; GIANNARINI, L.; SAMPOGNARO, S.; PARRONCHI, P.; MANETTI, R.; ANNUNZIATO, F.; LIVI, C. Progesterone favors the development of human $\mathrm{T}$ helper cells producing Th2-type cytokines and promotes both IL-4 production and membrane CD30 expression in established Th1 cell clones. Journal of Immunology, Baltimore, v. 155, n. 1, p. 128-133, 1995. 
PIJNENBORG, R.; BLAND, J. M.; ROBERTSON, W. B.; BROSENS, I. Utero placental arterial changes related to interstitial trophoblast migration in early human pregnancy. Placenta, London, v. 4, p. $397-413,1983$.

PREMAWARDHANA, L. D.; PARKES, A. B.; JOHN, R.; HARRIS, B.; LAZARUS, J. H. Thyroid peroxidase antibodies in early pregnancy: utility for prediction of postpartum thyroid dysfunction and implications for screening. Thyroid, New York, v. 14, n. 8, p. 610-615, 2004.

RANDOLPH, S. S.; GOOLEY, T. A.; WARREN, E. H.; APPELBAUM, F. R.; RIDDELL, S. R. Female donors contribute to a selective graft-versusleukemia effect in male recipients of HLA-matched, related hematopoietic stem cell transplants. Blood, New York, v. 103, p. 347-352, 2004.

REDLINE, R. W.; MCKAY, D. B.; VAZQUEZ, M. A.; PAPAIOANNOU, V. E.; LU, C. Y. Macrophage functions are regulated by the substratum of murine decidual stromal cells. The Journal of Clinical Investigation, New Haven, v. 85, n. 6, p. 1951-1958, 1990.

REINHARD, G.; NOLL, A.; SCHLEBUSH, H.; MALLMAN, P.; RUECKER, A. V. Shifts in the Th1/Th2 balance during human pregnancy correlate with apoptotic changes. Biochemical and biophysical research communications, New York, v. 245, p. 933-938, 1998.

ROCHESTER, D. B.; DAVIES, T. F. Increased risk of Graves' disease after pregnancy. Thyroid, New York, v. 15, p. 1287-1290, 2005.

ROOK, A. H.; KEHRL, J. H.; WAKEFIELD, L. M.; ROBERTS, A. B.; SPORN, M. B.; BURLINGTON, D. B.; LANE, H. C.; FAUCI, A. S. Effects of transforming growth factor $B$ on the functions of natural killer cells: depressed cytolytic activity and blunting of interferon responsiveness. Journal of Immunology, Baltimore, v. 136, n. 10, p. 39163920, 1986.

SAITO, S. Cytokine network at the feto-maternal interface. Journal of Reproductive Immunology, Amsterdam, v. 47, n. 2, p. 87-103, 2000.
SARAFANA, S.; COELHO, R.; NEVES, A.; TRINDADE, J. C. Aspectos da imunologia da gravidez. Acta Medica Portuguesa, Lisboa, v. 20, p. 355-358, 2007.

SOMERSET, D. A.; ZHENG, Y.; KILBY, M. D.; SANSOM, D. M.; DRAYSON, M. T. Normal human pregnancy is associated with an elevation in the immune suppressive $\mathrm{CD} 25+\mathrm{CD} 4+$ regulatory T-cell subset. Immunology, Oxford, v. 112, n. 1, p. 38-43, 2004.

SZEKERES-BARTHO, J.; AUTRAN, B.; DEBRE, P.; ANDREU, G.; DENVER, L.; CHAOUAT, G. Immunoregulatory effects of a suppressor factor from healthy pregnant women's lymphocytes after progesterone induction. Cellular Immunology, New York, v. 122, n. 2, p. 281-94, 1989.

SZEKERES-BARTHO, J.; KILAR, F.; FALKAY, G.; CSERNUS, V.; TOROK, A.; PACSA, A. S. The mechanism of the inhibitory effect of progesterone on lymphocyte cytotoxicity: I. Progesterone-treated lymphocytes release a substance inhibiting cytotoxicity and prostaglandin synthesis. American Journal of Reproductive Immunology and Microbiology, New York, v. 9, p. 15-18, 1985.

SZEKERES-BARTHO, J.; WEGMANN, T. G. A progesterone-dependent immunomodulatory protein alters the Th1/Th2 balance. Journal of Reproductive Immunology, Amsterdam, v. 31, p. 81-95, 1996.

TAKAMI, A.; SUGIMORI, C.; FENG, X.; YACHIE, A.; KONDO, Y.; NISHIMURA, R.; KUZUSHIMA, K.; KOTANI, T.; ASAKURA, H.; SHIOBARA, S.; NAKAO, S. Expansion and activation of minor histocompatibility antigen $\mathrm{HY}$ specific $\mathrm{T}$ cells associated with graft-versus-leukemia response. Bone Marrow Transplantation, Basingstoke,v. 34, n. 8, p.703-709, 2004.

VERDIJK, R. M.; KLOOSTERMAN, A.; POOL, J.;VAN DE KEUR, M.; NAIPAL, A. M.;VAN HALTEREN, A. G.; BRAND, A.; MUTIS, T.; GOULMY, E. Pregnancy induces minor histocompatibility antigen-specific cytotoxic $\mathrm{T}$ cells: implications for stem cell transplantation and immunotherapy. Blood, New York, v. 103, p.19611964, 2004. 
VICENTE, F.; SERRANO, F.; CAMPOS, A.; GASPAR, G. Embrião, um transplante com sucesso? Arquivos da Maternidade Alfredo da Costa, Lisboa, v. 16, n. 1, maio 2000.

WATANABE, M.; IWATANI, Y.; KANEDA, T.; HIDAKA, Y.; MITSUDA, N.; MORIM, Y.; AMINO, N. Changes in T, B, and NK lymphocyte subsets during and after normal pregnancy. American Journal of Reproductive Immunology, New York, v. 37, n. 5, p. 368-377, 1997.

WEETMAN, A. P. The immunology of pregnancy. Thyroid, New York, v. 9, p. 643-646, 1999.

ZENCLUSSEN, A. C.; FEST, S.; BUSSE, P.; JOACHIM, R.; KLAPP, B. F.; ARCK, P. C. Questioning the Th1/Th2 paradigm in reproduction: Peripheral levels of IL-12 are down-regulated in miscarriage patients. American Journal of Reproductive Immunology, New York, v. 48, n. 4, p. 245-51, 2002.

ZICARI, A.; TICCONI, C.; REALACCI, M.; CELA, O.;SANTANGELO, C.; PIETROPOLLI, A.;RUSSO, M.A.;PICCIONE, E. Hormonal regulation of cytokine release by human fetal membranes at term gestation: effects of oxytocin, hydrocortisone and progesterone on tumour necrosis factor-alpha and transforming growth factor-beta 1 output. Journal of Reproductive Immunology. v. 56, n. 1-2, p. 123-36, 2002. 
